\title{
Myeloblast to Leukocyte Ratio
}

National Cancer Institute

\section{Source}

National Cancer Institute. Myeloblast to Leukocyte Ratio. NCI Thesaurus. Code C64825.

The determination of the ratio of myeloblasts compared to leukocytes in a blood sample.

The measurement may be expressed as a ratio or percentage. 